Revista Brasileira de Cartografia

ISSN 1808-0936 | https://doi.org/10.14393/revbrascartogr

Sociedade Brasileira de Cartografia, Geodésia, Fotogrametria e Sensoriamento Remoto

\title{
Símbolos Pontuais para o Mapeamento Topográfico em Escala Grande
}

\section{Point Symbols for Large-scale Topographic Mapping}

\author{
Flávia Silveira ${ }^{1}$, Adriana Alexandria Machado $^{2}$, Andrea Faria Andrade ${ }^{3}$ e Silvana Philippi Camboim ${ }^{4}$
}

1 Universidade Federal do Paraná, Programa de Pós-Graduação em Ciências Geodésicas, Curitiba, Brasil. flavia.silveira@ufpr.br ORCID: https://orcid.org/0000-0002-9235-2227

2 Universidade Federal do Paraná, Programa de Pós-Graduação em Ciências Geodésicas, Curitiba, Brasil.

adri.alexandria@gmail.com

ORCID: https://orcid.org/0000-0003-1013-2050

3 Universidade Federal do Paraná, Programa de Pós-Graduação em Ciências Geodésicas, Curitiba, Brasil. afariandrade @ gmail.com

ORCID: https://orcid.org/0000-0002-5378-2451

4 Universidade Federal do Paraná, Programa de Pós-Graduação em Ciências Geodésicas, Curitiba, Brasil.

silvanacamboim@gmail.com

ORCID: https://orcid.org/0000-0003-3557-5341

Resumo: Existe a falta de uma simbologia pontual padronizada para ser aplicada ao mapeamento topográfico em escala grande no Brasil. Ademais, há a necessidade da discussão de conceitos da percepção visual para o desenvolvimento dos símbolos cartográficos. Nesse sentido, este trabalho propõe símbolos pontuais para mapas em escala grande (1:2.000). Essa abordagem é construída com base nos conceitos de percepção visual para a proposição dos símbolos e em testes de preferência dos usuários por esses símbolos para o mapeamento topográfico em escala grande. O teste de preferência foi aplicado após tarefas de leitura de mapas envolvendo os níveis de navegação e mensuração propostos por Board (1978). Um total de 121 participantes realizou o teste em ambiente digital. O teste visou avaliar se símbolos com contorno e com fundo branco são mais bem detectados, discriminados e reconhecidos no contexto do mapa. Os símbolos que não foram considerados eficazes de acordo com esta metodologia proposta por Clarke (1989) foram reformulados, a fim de que possíveis falhas no processo da criação dos símbolos fossem corrigidas. Os símbolos testados e não testados foram disponibilizados para a comunidade acadêmica através da plataforma Github do Laboratório Geoespacial Livre da Universidade Federal do Paraná, para que possam ser utilizados e aprimorados por pesquisadores e usuários da área.

Palavras-chave: Mapeamento topográfico. Cartografia. Simbologia. Símbolos pontuais.

\begin{abstract}
There is a lack of a current standardized symbology to be applied to large-scale topographic mapping in Brazil. In addition, there is a need to discuss concepts of visual perception for the development of cartographic symbols. In this way, this work proposes point symbols for large-scale topographic mapping (1:2.000). This approach is done based on concepts of visual perception to propose the symbols and on user preference tests for these symbols for large-scale topographic mapping. The preference tests were applied after maps reading tasks involving the levels of navigation and measurement proposed by Board (1978). In total 121 participants took the test in a digital environment. The test aimed to evaluate whether symbols presented with outline and white background are better detected, discriminated, and recognized on the context of the map. The symbols that are not considered effective according to the methodology proposed by Clarke (1989) were reformulated, so that possible flaws in the process of creating the symbols were corrected. The tested and untested symbols were made available to the academic community through the Github platform of the Laboratório Geoespacial Livre from Universidade Federal do Paraná, so they can be used and improved by researchers and users of the area.
\end{abstract}

Keywords: Topographic mapping. Cartography. Symbology. Symbols. 


\section{INTRODUÇÃO}

A simbologia cartográfica é a linguagem utilizada no mapeamento, seja ele temático ou topográfico, para a representação de suas feições, levando em consideração a escala de representação dos dados e seu nível de generalização. De acordo com Deeb, Ooms e De Maeyer (2017), o fato dos mapas serem amplamente utilizados por diferentes grupos de usuários, a legibilidade dos mapas tem sido uma preocupação no âmbito da cartografia desde o início do desenvolvimento cartográfico.

MacEachren (1994) considera que o conjunto dos símbolos, incluindo seus significados, compõe a linguagem cartográfica, os quais são agentes no processo de comunicação cartográfica e é por meio deles que o usuário de um mapa é capaz de decodificar a mensagem transmitida, portanto, a qualidade dos símbolos está diretamente relacionada com a capacidade de leitura do mapa pelos usuários.

De acordo com Santil (2008) a interpretação dos símbolos do mapa não é apenas um processo físico, e sim um procedimento físico e mental complexo, no qual o usuário é capaz de reconhecer arranjos e padrões espaciais através da ordenação do estímulo visual, o qual está submetido às teorias de percepção e cognição visual.

A percepção visual é concebida a partir da observação, por parte do usuário, das informações referente às cores, formas e tamanhos dos símbolos e da construção, a partir destes, de um panorama da realidade, na qual se relaciona ao processo de cognição (ANDRADE, 2014). De acordo com Oliveira (2012) os conhecimentos já desenvolvidos nas áreas de comunicação, percepção e cognição visual, adequados às especificidades da Cartografia, fornecem diretrizes para soluções de projeto cartográfico.

A percepção visual é um elemento básico na comunicação cartográfica, e a Teoria da Gestalt e da Semiótica podem ser usadas como base para o desenvolvimento de símbolos cartográficos, pois referem-se ao processamento visual da forma e relacionam-se diretamente no processo de leitura da simbologia dos mapas. A eficácia da comunicação cartográfica deve ser avaliada a fim de que se possa mensurar o quanto a transferência de informação é facilitada pelo mapa (MERSEY, 1990). MacEachren (1982) sugere a utilização de tarefas para avaliar a eficácia de um mapa, e segundo o autor, a capacidade do usuário em executar as tarefas com um mapa está diretamente relacionada com a qualidade apresentada por este produto cartográfico.

Olson (1976) também compreende que a efetividade das representações cartográficas é possível de ser avaliada através de tarefas. $\mathrm{O}$ autor realizou experiências com a utilização de mapas temáticos e como resultado, estabeleceu três níveis distintos de tarefas de leitura de mapas: a comparação de símbolos isoladamente a fim de realizar a identificação da sua forma e tamanho; a comparação de grupos de símbolos; e a utilização do mapa como ferramenta de tomada de decisão.

Assim como Olson (1976), Board (1978) estabeleceu diferentes níveis de complexidade para a leitura dos mapas e fundou-os sobre princípios da psicologia para compreender como a leitura do mapa e os processos mentais humanos se relacionam. Os níveis estabelecidos por Board (1978) variam desde a navegação, considerada o nível mais simples de tarefas a serem realizadas com o mapa, passando pelo nível intermediário denominado mensuração até chegar ao nível visualização, considerado o mais complexo, o qual o autor enfatiza a reconstituição de paisagens a partir do mapa.

Para aumentar a eficácia de um mapa, sugere-se a padronização da simbologia, a fim de que a influência dos aspectos culturais de quem o desenvolve sejam menores, e ainda para que se diminua a diferença de interpretação dos usuários, baseado nas variáveis idade e ser ou não especialista no uso de mapas. Segundo Board (1991) estes aspectos interferem nas habilidades cognitivas de recordar, de armazenar, entre outras, que podem afetar tanto tarefas simples, como a comparação entre símbolos, como as de maior complexidade, que envolvam inferências sobre as relações entre os mesmos. É imprescindível que, a fim de melhorar a eficácia dos mapas topográficos, se padronize símbolos baseados em conceitos de percepção visual, para que seja minimizada a subjetividade no desenvolvimento.

Desta forma, esse artigo visa contribuir na proposição, desenvolvimento e teste de um conjunto de símbolos pontuais para o mapeamento topográfico em escala grande (1:2.000) desenvolvido a partir de conceitos de percepção visual da forma, teoria da Gestalt e Semiótica. Os símbolos propostos foram submetidos a um teste composto por diversas tarefas de leitura de mapas a fim de avaliar a eficácia no contexto do mapa e definir um conjunto final de símbolos. 


\section{METODOLOGIA}

\subsection{Base cartográfica e de símbolos utilizados}

\subsubsection{BASE CARTOGRÁFICA}

A base cartográfica utilizada para o estudo foi desenvolvida pela Diretoria de Serviço Geográfico (DSG) do Exército Brasileiro em virtude do evento da Copa Mundial de Futebol ocorrido no ano de 2014 e corresponde a uma área de 1.300 metros por 900 metros em torno do Estádio Joaquim Américo Guimarães, localizado na cidade de Curitiba-PR. A localização da base cartográfica apresenta-se destacada na Figura 01.

Figura 1 - Localização da área de estudo.

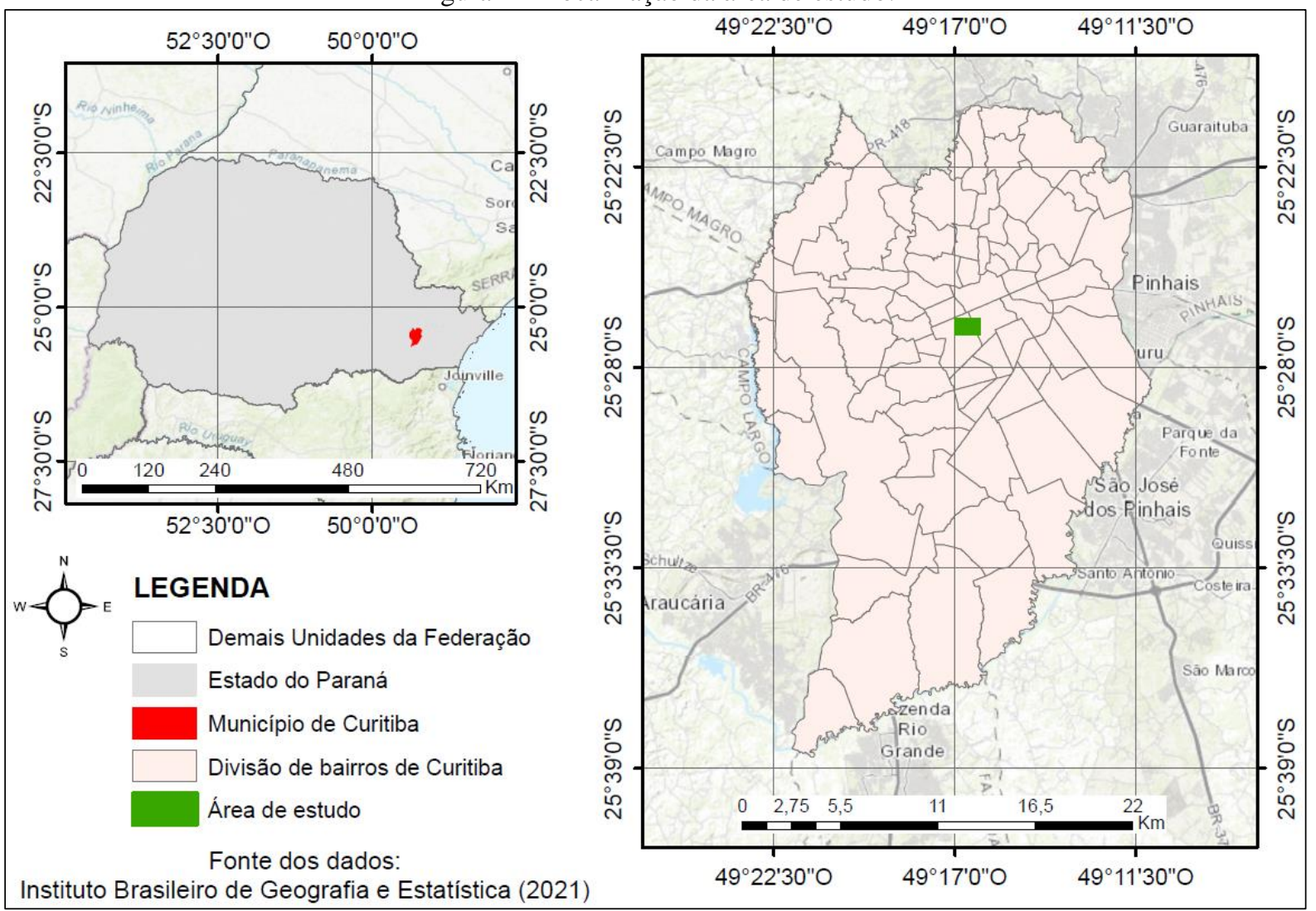

Fonte: Os autores (2021).

A base cartográfica utilizada é compatível com o nível de detalhamento da escala 1:2.000 e representa através da primitiva gráfica área, o arruamento, quadras, edificações, parques, praças e os principais equipamentos urbanos.

Para realizar a adição dos dados referentes às edificações comerciais a esta base, foram geocodificados os estabelecimentos comerciais a partir da base tabular de alvarás disponível no Portal de Dados Abertos de Curitiba, disponibilizados pela Prefeitura Municipal de Curitiba (2020), os quais passaram a ser representados no formato vetorial pela primitiva gráfica ponto agregando as informações do estabelecimento comercial como atributos da camada.

\subsubsection{SIMBOLOGIA CARTOGRÁFICA UTILIZADA}

Para as feições de área foram utilizados os símbolos do Manual Técnico T34-700, Sluter et al. (2019) e Pisetta (2018). A Quadro 1 apresenta a fonte dos símbolos utilizados para representar as feições (vegetação, campo, praça, campo/quadra, arquibancada, massa d'água, edificações, edificação de saúde, edificação religiosa, edificação militar, edificação de ensino, edificação de energia, edificação de lazer, edificação de comunicação, edificação de comércio/ serviço, delegacia de polícia, quadra, canteiro central, piscina e 
arruamento) foram simbolizadas de acordo apresentadas com a primitiva gráfica de área.

Quadro 1 - Fonte dos símbolos utilizados para representar as feições apresentadas com a primitiva gráfica de área.

\begin{tabular}{|l|c|}
\hline \multicolumn{1}{|c|}{ Feição } & Fonte da simbologia \\
\hline Arquibancada & Sluter et al. (2019) \\
Arruamento & Pisetta (2018) \\
\hline Calçada & \\
\hline Campo/quadra & \\
Canteiro central & \\
Eelegacia de polícia & Sluter et al. (2019) \\
Edificaçã̃o de comércio/serviço & \\
Edificação de comunicação & \\
Edificação de energia & \\
Edificação de ensino & \\
Edificação de lazer & \\
Edificação de saúde & \\
Edificação militar & Manual T34-700 (2000) \\
Edificação religiosa & \\
\hline Escadaria & Sluter et al. (2019) \\
\hline Massa d’água & \\
Piscina & \\
Praça & \\
Quadra & \\
Vegetação & \\
\hline
\end{tabular}

Fonte: Os autores (2021).

\subsection{Projeto dos símbolos pontuais}

Os símbolos cartográficos pontuais foram projetados para representar as feições presentes na base cartográfica. Foram elas: campo ou quadra esportiva, edificação de saúde, edificação religiosa, edificação pública ou militar, edificação de ensino, edificação de lazer, edificação de comunicação, delegacia de polícia, edificação comercial, semáforo e ponto de ônibus. As edificações comerciais foram subdivididas em oito tipos para os quais foram desenvolvidos símbolos pontuais específicos, visto que a sua natureza era discriminada na camada da base cartográfica utilizada.

Os símbolos foram desenvolvidos com base no Manual técnico T34-700, no Guia Brasileiro de Sinalização Turística, na tese de Andrade (2014), no estudo de Sluter et al. (2019), nas plataformas de mapeamento Google Maps e Open Street Map e na biblioteca de símbolos do National Park Service (NPS) dos EUA. Foram feitas alterações nas simbologias já propostas para realizar a compatibilização dos símbolos com a escala 1:2.000 utilizada neste estudo. De acordo com Granha (2001) quanto menos unidades compositivas, mais legíveis são os símbolos quando submetidos à redução, melhorando sua clareza.

Forrest e Castner (1985) constataram em seu trabalho que símbolos com maior quantidade de preto na sua composição são melhor identificados no mapa comparados a aqueles que possuem somente as linhas externas de sua forma, tal constatação também foi observada no trabalho de Andrade (2014). Seguindo as recomendações destes autores da teoria da Gestalt optou-se pelo desenvolvimento dos símbolos em preto (exceto para os símbolos de edificação de saúde e farmácia), com o preenchimento total de suas formas e com poucas unidades compositivas, a fim de exaltar aspectos como equilíbrio e simplicidade.

Taura, Sluter e Firkowski (2010) concluíram que o tamanho mínimo para a discriminação do símbolo geométrico do tipo quadrado vazado é 0,5 milímetros. Entretanto, como os símbolos desenvolvidos seriam inseridos dentro de um quadrado vazado, foi utilizado o tamanho de 5 milímetros para o quadrado e de 4 milímetros para os símbolos nele inseridos, de acordo com o trabalho de Araújo et al. (2016). 


\subsection{Testes de percepção visual}

A fim de validar os dezenove símbolos pontuais desenvolvidos, foram realizados testes de percepção visual. Para tanto, a representação dos símbolos ocorreu em dois mapas digitais distintos para auxiliar na validação de hipóteses estabelecidas. No primeiro, os símbolos foram representados com um contorno quadrangular com 0,2 milímetros de espessura em preto (RGB - 0,0,0) e com o fundo branco (RGB - 255, 255, 255), e no segundo os símbolos pontuais foram representados sem contorno ou fundo padronizado.

Os 121 voluntários do teste foram estudantes de graduação dos cursos de Agronomia, Engenharia Cartográfica e de Agrimensura, Engenharia Ambiental e Geografia dos programas de Pós-Graduação em Ciências Geodésicas e Geografia, todos da Universidade Federal do Paraná (UFPR). As idades variam entre 17 e 48 anos, sendo 48 participantes do gênero feminino e 73 do masculino. Apenas um participante do teste apresentava idade superior a 40 anos, idade que a visão humana sofre uma degradação natural, neste sentido é sugerido que este tópico seja abordado em pesquisas futuras. Aproximadamente, setenta e nove por cento (79,34\%) dos participantes informaram apresentar algum conhecimento no software QGIS, seja ele básico, intermediário ou avançado. O nível de conhecimento no software QGIS foi levado em consideração, visto que a análise de algumas tarefas propostas no teste foram avaliadas de acordo com o tempo que os participantes dispensavam para concluí-la, e o nível de conhecimento dos participantes no software poderiam influenciar em seu desempenho.

Os voluntários foram divididos em dois grupos de forma aleatória. O grupo 01 composto por 58 participantes, realizou o teste com o mapa que continha somente os símbolos pontuais, sem fundo e sem contorno. O grupo 2, composto por 63 participantes, realizou o teste com o mapa que continha os símbolos pontuais com fundo branco e contorno. Os mapas utilizados no teste de percepção foram apresentados em plataforma digital, através do software QGIS e também através de recortes dos mapas apresentados na plataforma Google Forms. Os computadores utilizados para o teste apresentavam dimensão de 20 polegadas.

Os símbolos apresentados nos mapas foram exibidos com a mesma orientação, já que a percepção visual de uma imagem se modifica conforme a orientação (ARNHEIM, 2011), o que pode influenciar diretamente a detecção, a discriminação e o reconhecimento da simbologia. O teste de avaliação dos símbolos seguiu as tarefas dos níveis de leitura de mapa propostos por Board (1978).

\subsubsection{HIPÓTESES}

A fim de embasar as tarefas dos testes, foram definidas as seguintes hipóteses:

a) hipótese 01: a eficácia do mapa aumenta à medida que aumenta o contraste entre o símbolo(figura) e o fundo e quando o símbolo possui contorno. A confirmação desta hipótese seria ou não constatada com a análise da quantidade de pessoas, por grupo, que localizaram o símbolo da agência bancária do Santander e do estabelecimento de refeição mais próximo a esta agência, bem como na análise do tempo médio gasto pelos grupos 01 e 02 na localização dos pontos solicitados;

b) hipótese 02: nível de conhecimento da ferramenta não influencia na localização dos símbolos. A hipótese 02 é baseada no trabalho de Forrest e Castner (1985) e Andrade (2014). Forrest e Castner (1985) encontraram como resultado de seu trabalho que a frequência de uso de mapas não tem relação com o tempo médio gasto pelos participantes na localização dos símbolos. Andrade (2014) obteve como resultado do seu trabalho que não houve dependência entre a detecção dos símbolos e a experiência do uso de mapas turísticos. Ambos os autores obtiveram este resultado analisando a utilização de mapas turísticos em formato analógico. O presente trabalho visou relacionar o conhecimento dos participantes no software QGIS e a localização dos símbolos solicitados em mapas topográficos apresentados em formato digital;

c) hipótese 03: o contorno e o maior contraste entre o símbolo (figura) e o fundo influencia na identificação (detecção e discriminação) e por consequência na contagem dos símbolos no mapa. A constatação ou não desta hipótese poderia ser verificada observando a quantidade de pessoas que contaram exatamente o número de pontos de ônibus existentes no mapa apresentado para elas; 
d) hipótese 04: o reconhecimento dos símbolos é favorecido quando existe maior contraste entre a figura e o fundo e quando o símbolo possui contorno. A confirmação desta hipótese seria ou não constatada com a análise da quantidade de pessoas, por grupo, que reconheceram assertivamente o significado de cada símbolo apresentado no mapa.

\subsubsection{TAREFAS}

As tarefas realizadas para a validação das hipóteses estão relacionadas abaixo:

a) tarefa 01 - detecção, discriminação e reconhecimento: a fim de avaliar as hipóteses 01 e 02 , na primeira tarefa o participante deveria procurar pelo banco Santander (ponto 1) no mapa. Posteriormente, deveria procurar por um estabelecimento que pudesse realizar uma refeição (ponto 2) e que se localizasse mais próximo ao primeiro ponto. Os participantes deveriam adicionar uma feição pontual sobre o ponto 1 e outra sobre o ponto 2 utilizando a ferramenta de edição de camadas no projeto do QGIS já disponível no computador de cada participante. A adição da feição pontual foi necessária para auxiliar na avaliação posterior do teste e determinar os resultados obtidos. Esta tarefa permitiu avaliar as tarefas do nível de leitura de mapas navegação proposto por Board (1978): procurar, orientar-se e procurar por um destino, identificar um destino. De acordo com o processo de categorização definido por Elzakker (2004), esta tarefa avalia a detecção, discriminação e reconhecimento dos símbolos;

b) tarefa 02 - detecção e discriminação: a fim de validar a hipótese 03, na segunda tarefa o participante deveria contar quantos pontos de ônibus existiam no mapa e informar este valor em um questionário elaborado no Google Forms. Esta tarefa permitiu avaliar as tarefas do nível de leitura de mapas navegação proposto por Board (1978): procurar, identificar e contar. De acordo com o processo de categorização definido por Elzakker (2004), esta tarefa avalia a detecção e discriminação dos símbolos;

c) tarefa 03 - reconhecimento: a fim de validar a hipótese inicial, apresentados diferentes trechos do mapa em um formulário online, o participante deveria, fora do ambiente do QGIS, reconhecer o significado de cada símbolo apresentado, agora sem seu respectivo topônimo. Para tanto, foram selecionadas cinco figuras de regiões diversas do mapa, que somadas apresentavam os dezenove símbolos pontuais desenvolvidos. Esta tarefa permitiu avaliar a tarefa do nível de leitura de mapas navegação proposto por Board (1978) que é reconhecer e, a tarefa de categorização definida por Elzakker (2004) denominada como reconhecimento.

\section{RESULTADOS}

\subsection{Símbolos pontuais desenvolvidos}

A Figura 2 apresenta os símbolos pontuais propostos e nas próximas seções são apresentadas as análises dos resultados das tarefas realizadas no processo de validação desses símbolos. 
Figura 2 - Símbolos pontuais desenvolvidos apresentados com e sem contorno.

\begin{tabular}{|c|c|c|c|c|c|}
\hline Eeiç̃ి & Sem & Com & Eeviñ & Sem & Com \\
\hline геदцы & & & Feição & & \\
\hline Agência bancária & & & Edificaçào religiosa & & \\
\hline Agência dos correios & & & Estabelecimento de refeição & & \\
\hline Campo/Quadra & & & Farmácia & & \\
\hline Comércio geral & & & Hotel & & \\
\hline Delegacia de polícia & & & Ponto de ônibus & & \\
\hline Edificação de comunicação & & & Posto de combustivel & & \\
\hline Edificação de ensino & & & Praça & & \\
\hline Edificaçåo de lazer & & & Semáforo & & \\
\hline Edificação de saúde & & & Supermercado & & \\
\hline Edificação pública & & & & & \\
\hline
\end{tabular}

Fonte: Os autores (2021).

\subsection{Análise dos resultados do teste de percepção}

Para analisar os resultados do teste de percepção foram utilizados testes estatísticos visando validar ou não a hipótese geral: símbolos que são apresentados sobre um fundo branco, acrescidos de um contorno que delimita a área de representação dos símbolos são melhor percebidos, no contexto do mapeamento topográfico apresentado em escala grande. A seguir são apresentados os resultados obtidos nas três tarefas que fizeram parte do teste de percepção visual.

\subsubsection{TAREFA DEDETECÇÃO, DISCRIMINAÇÃO E RECONHECIMENTO}

Nesta tarefa, foi avaliado se os participantes conseguiram executar as etapas (a) localizar a agência bancária do Santander e (b) localizar o estabelecimento para refeição mais próximo a agência, bem como, em caso afirmativo, o tempo dispensado para a execução de cada uma delas. Para avaliar a assertividade dos participantes do grupo 01 e 02 na execução desta tarefa, foi analisada a quantidade de participantes que foram capazes de localizar os pontos solicitados. Todos os participantes do grupo 01 (58 participantes) e do grupo 02 (63 participantes) localizaram o ponto 01 solicitado (agência bancária do Santander). Em relação aos resultados referentes ao ponto 02, estes são apresentados na Tabela 1 .

Tabela $1-$ Assertividade na localização do ponto 02 na tarefa 01 .

\begin{tabular}{l|c|c|c|c}
\hline \multirow{2}{*}{ Texto } & \multicolumn{2}{c|}{ Grupo 1 } & \multicolumn{2}{c}{ Grupo 2 } \\
\cline { 2 - 5 } & Número de pessoas & Porcentagem & Número de pessoas & Porcentagem \\
\hline $\begin{array}{l}\text { Localizou o } \\
\text { estabelecimento de } \\
\text { refeição }\end{array}$ & 46 & $79,31 \%$ & 55 & $87,30 \%$ \\
$\begin{array}{l}\text { Localizou, mas não era o } \\
\text { mais próximo }\end{array}$ & 8 & $13,79 \%$ & 5 & $7,93 \%$ \\
$\begin{array}{l}\text { Não era estabelecimento } \\
\text { de refeição }\end{array}$ & 4 & $6,89 \%$ & 3 & $4,76 \%$ \\
\hline
\end{tabular}

Fonte: Os autores (2021).

A análise da Tabela 1 demonstra a detecção do ponto 02 ocorreu de forma mais eficaz entre os 
participantes do grupo 02, ou seja, através do mapa que continha os símbolos pontuais com contorno e apresentados sobre um fundo branco. Além disso, a discriminação do símbolo do estabelecimento de refeição foi mais bem sucedido para o grupo 02. Quando o participante localiza um estabelecimento de refeição, mas não aquele mais próximo a agência bancária, significa que o indivíduo foi capaz de reconhecer o símbolo do estabelecimento de refeição, embora não tenha sido capaz de discriminar o símbolo mais próximo. O grupo 01 teve mais dificuldade no reconhecimento do símbolo do estabelecimento de refeição. No grupo 01 (6,89\%) identificaram outros símbolos como sendo locais para refeição, enquanto no grupo 02 foram $(4,76 \%)$.

A análise da assertividade da tarefa 01 pelos dois grupos permite afirmar que contorno e o fundo branco aplicados ao símbolo pontual auxiliaram na assertividade do grupo 02 na execução da tarefa 01 .

O tempo dispensado para a execução de cada etapa da tarefa 01foi obtido a partir de vídeos da gravação de tela dos participantes. Os dados de tempo foram analisados estatisticamente e os valores maiores do que os outliers (valores fora do intervalo entre o mínimo e o máximo) calculados foram retirados da análise a fim de não prejudicar as análises realizadas. A amplitude de tempo dispensado para a localização dos pontos pelo grupo 01 (405 segundos para o ponto 01 e 257 segundos para o ponto 02) é maior que para o grupo 02 (243 segundos para o ponto 01 e 145 segundos para o ponto 02). Isto significa que a dispersão dos dados foi maior para o grupo 01 do que para o grupo 02 . Ou seja, houve maior diferença de tempo entre o participante que localizou mais rapidamente e aquele que demorou mais tempo para localizar o ponto 01 e o ponto 02 no grupo 01 comparativamente ao grupo 02. A Tabela 2 apresenta a média e o desvio padrão do tempo utilizado por cada um dos grupos na localização dos pontos 01 e 02.

Tabela 2 - Média e desvio padrão para a localização dos pontos 01 e 02 por grupo.

\begin{tabular}{l|c|c|c|c}
\hline \multirow{2}{*}{ Texto } & \multicolumn{2}{|c|}{ Ponto 1 } & \multicolumn{2}{c}{ Ponto 2 } \\
\cline { 2 - 5 } & Média (segundos) & $\begin{array}{c}\text { Desvio padrão } \\
\text { (segundos) }\end{array}$ & Média (segundos) & $\begin{array}{c}\text { Desvio padrão } \\
\text { (segundos) }\end{array}$ \\
\hline Grupo 1 & 112,86 & 62,01 & 50,80 & 46,38 \\
Grupo 2 & 86,63 & 47.26 & 43,10 & 26,72 \\
\hline
\end{tabular}

Fonte: Os autores (2021).

Analisando-se os valores apresentados na Tabela 2 percebe-se que o tempo médio de localização dos pontos 01 e 02 foi inferior para o grupo 02 , uma diferença de 26,23 e 7,7 segundos respectivamente em relação ao grupo 01. A análise das médias permite concluir que o grupo 02 foi mais eficaz na detecção os pontos $01 \mathrm{e}$ 02. O desvio padrão do tempo de localização dos pontos pelo grupo 02 foi inferior ao do grupo 01. Isto implica que o tempo de localização dos pontos pelos participantes do grupo 02 foi mais homogêneo que o do grupo 01. Para realizar a comparação do tempo médio utilizado por cada grupo na localização dos pontos 01 e 02 foi realizado o teste de hipótese $T$-Student, dado que são duas amostras independentes e pequenas (Triola, 1999).

As hipóteses delimitadas para a realização do teste foram as seguintes. A hipótese $H_{0}$ afirma que as médias referentes ao tempo gasto para localização dos pontos solicitados para os grupos 01 e 02 são estatisticamente iguais e a hipótese $H_{l}$ afirma que as médias são estatisticamente diferentes. $\mathrm{O}$ nível de significância foi de 0,05 e o nível de confiança foi de 0,95 , ou seja, acredita-se que para $95 \%$ dos casos, o resultado obtido é verdadeiro e reflete a realidade. Caso o valor de $t$ calculado seja maior que o valor de $t$ tabelado, rejeita-se $H_{0}$ para um nível de significância de 0,05 , ou seja, há evidências estatísticas que as médias do grupo 01 e 02 são diferentes, caso contrário, aceita-se a hipótese $H_{0 .} \mathrm{O}$ valor encontrado para os elementos do teste e seu respectivo p-valor é apresentado na Tabela 3.

Tabela 3 - Coeficientes calculados para o teste t-Student.

\begin{tabular}{l|c|c}
\hline \multicolumn{1}{c|}{ Coeficiente } & Ponto 1 & Ponto 2 \\
\hline Desvio padrão médio para as amostras & 3005,58 & 2402,56 \\
Valor calculado referente ao teste T & 2,63 & 2,13 \\
p-valor & 0,004829 & 0,017607 \\
\hline
\end{tabular}

Fonte: Os autores (2021).

O valor tabelado do teste T-Student para um nível de confiança de $95 \%$, com 120 graus de liberdade é de 1,98. Como é possível observar na Tabela 3, o valor do coeficiente $t$ calculado para os pontos 01 e 02 foi 
maior que o valor tabelado. Isto quer dizer que existem evidências estatísticas para rejeitar a hipótese $H_{0}$. Ou seja, a diferença entre as médias dos grupos 01 e 02 é significativa e sendo assim é possível afirmar que os participantes do grupo 02 foram mais eficazes no processo de detecção dos pontos solicitados.

$\mathrm{O}$ valor de significância do teste, definido em 0,05 é maior que o p-valor calculado,

Em síntese, a detecção, discriminação e reconhecimento dos símbolos na tarefa 01 foi melhor executada pelos participantes do grupo 02. Concluiu-se, portanto, que o contorno e o fundo branco auxiliaram nos processos de categorização dos símbolos definidos por Elzakker (2004) e nas tarefas do nível de leitura de mapas de navegação propostos por Board (1978).

\subsubsection{TAREFA DE DETECÇÃO E DISCRIMINAÇÃO}

A avaliação da segunda tarefa consistiu em comparar o número de pontos de ônibus informado pelos participantes com o número real de pontos de ônibus existentes no mapa (12). Como resultado da tarefa obtevese uma tabela de frequência (Tabela 4) dos números de pontos de ônibus reconhecidos por ambos os grupos.

Tabela 4- Frequência do número de pontos de ônibus localizados.

\begin{tabular}{l|c|c|c|c}
\hline \multirow{2}{*}{$\begin{array}{l}\text { Número de pontos de } \\
\text { onibus }\end{array}$} & \multicolumn{2}{|c|}{ Grupo 1 } & \multicolumn{2}{c}{ Grupo 2 } \\
\cline { 2 - 5 } & Número de pessoas & Porcentagem & Número de pessoas & Porcentagem \\
\hline 7 & 1 & $1,72 \%$ & - & $0,00 \%$ \\
9 & 1 & $1,72 \%$ & - & $0,00 \%$ \\
10 & 5 & $8,62 \%$ & 4 & $6,35 \%$ \\
11 & 6 & $10,34 \%$ & 7 & $11,11 \%$ \\
12 & 20 & $34,48 \%$ & 30 & $47,62 \%$ \\
13 & 18 & $31,03 \%$ & 17 & $26,98 \%$ \\
14 & 7 & $12,07 \%$ & 2 & $3,17 \%$ \\
15 & - & $0,00 \%$ & 3 & $4,76 \%$ \\
\hline
\end{tabular}

Fonte: Os autores (2021).

Para ambos os grupos, a moda do número de pontos de ônibus reconhecidos no mapa foi 12. Entretanto, para o grupo 02 , o percentual de participantes que localizaram 12 pontos de ônibus foi maior $(47,62 \%)$ comparativamente ao grupo $01(34,48 \%)$. Para avaliar a frequência do número de pontos de ônibus informados pelos participantes do teste, foi utilizado o teste Qui-Quadrado. De acordo com Triola (1999), este teste verifica se a frequência de um determinado acontecimento observado em uma amostra se desvia significativamente ou não da frequência com que ele é esperado. Para a execução do teste foram delimitadas duas hipóteses. A primeira delas $H_{0}$, diz que não há diferença significativa entre a frequência esperada e a frequência observada. A segunda $H_{1}$, diz que há diferença significativa entre a frequência esperada e a frequência observada.

A este teste foi atribuído nível de significância de 0,05 . Caso o valor de $t$ calculado seja maior que o valor de $t$ tabelado, rejeita-se $H_{0}$ para um nível de significância de 0,05 . Ou seja, há evidências estatísticas de que as médias do grupo 01 e 02 são diferentes. Caso contrário, a hipótese $H_{0}$ é aceita.

A frequência esperada foi definida em zero para todos os números de pontos de ônibus que não fosse o número real de pontos de ônibus contidos no mapa (12). Para o número de 12 pontos de ônibus, a frequência esperada foi definida como o valor total da amostra de cada grupo: 58 para o grupo 01 e 63 para o grupo 02 . Os valores da frequência observada (f.o.) e da frequência esperada (f.e.) para ambos os grupos são apresentados na Tabela 5.

Tabela 5- Frequências observadas e esperadas para o grupo 01.

\begin{tabular}{l|c|c|c|c|c|c|c|c|c}
\hline & $\begin{array}{c}\text { Número } \\
\text { de pontos }\end{array}$ & $\mathbf{7}$ & $\mathbf{9}$ & $\mathbf{1 0}$ & $\mathbf{1 1}$ & $\mathbf{1 2}$ & $\mathbf{1 3}$ & $\mathbf{1 4}$ & $\mathbf{1 5}$ \\
\hline \multirow{2}{*}{ Grupo 1} & f.o. & 1 & 1 & 5 & 6 & 20 & 18 & 7 & 0 \\
& f.e. & 0 & 0 & 0 & 0 & 58 & 0 & 0 & 0 \\
\multirow{2}{*}{ Grupo 2} & f.o. & 0 & 0 & 4 & 7 & 30 & 17 & 2 & 3 \\
& f.e. & 0 & 0 & 0 & 0 & 63 & 0 & 0 & 0 \\
\hline
\end{tabular}

Fonte: Os autores (2021). 
A partir dos valores apresentados na Tabela 5 foi possível calcular os valores do Qui-Quadrado $\left(X^{2}\right)$ para os grupos 01 e 02, através da soma dos quadrados da diferença entre a frequência observada e a frequência esperada, dividido pela soma das frequências esperadas. O Qui-Quadrado do grupo 01 teve como resultado o valor de 32,41 e o grupo 02 de 23,11. O valor do Qui-Quadrado tabelado para o grupo 01, com 57 graus de liberdade, foi de 33,15. O valor do Qui-Quadrado tabelado para o grupo 02, com 62 graus de liberdade foi de 36,71. Ambos com nível de significância de 0,05 .

Para os dois grupos observa-se que o valor do Qui-Quadrado calculado é menor que o Qui-Quadrado tabelado. Este resultado permite aceitar a hipótese $H_{0}$, ou seja, não há diferença significativa entre a frequência esperada e a frequência observada na localização dos pontos de ônibus para os dois grupos.

É possível verificar que para o grupo 02 os valores do Qui-Quadrado calculado e tabelado foram mais discrepantes entre si, se comparados aos valores do grupo 01. Isto permite concluir que para o grupo 02, a frequência observada está mais próxima da frequência esperada. Esta análise estatística, oferece indícios para se concluir que símbolos com contorno e apresentados sobre fundo branco são melhor detectados e discriminados do que que símbolos apresentados sem estes elementos, auxiliando na tarefa de contagem destes símbolos no mapa.

\subsubsection{TAREFA DE RECONHECIMENTO}

A terceira tarefa visou avaliar a compreensão semântica dos símbolos pelos participantes do teste. Para realizar a avaliação dos resultados obtidos com esta tarefa foi utilizado o Método da Compreensão de Blok (1987) para avaliar respostas abertas. Para este teste são usadas quatro possíveis classes de respostas: resposta correta; resposta correta associativa; resposta incorreta e; nenhuma resposta.

As respostas corretas foram consideradas as que o participante acertou o real significado do símbolo. As respostas corretas associativas, aquelas que possuíam alguma relação semântica com o significado do símbolo, conforme descrito no Quadro 2. As respostas incorretas foram consideradas aquelas que não possuíam nenhuma relação semântica com o símbolo. Quando o participante afirmou não saber o significado do símbolo, foi considerada a classe nenhuma resposta.

Quadro 2 - Feições de área também representadas por símbolos pontuais.

\begin{tabular}{|l|l|}
\hline \multicolumn{1}{|c|}{ Feição } & \multicolumn{1}{|c|}{ Resposta correta associativa } \\
\hline Agência bancária & Agência bancária ou banco \\
\hline Campo/Quadra & $\begin{array}{l}\text { Quadra esportiva, ginásio de esporte, local de prática esportiva, } \\
\text { campo de futebol ou quadra poliesportiva }\end{array}$ \\
\hline Correio & Agência dos Correios ou Correios \\
\hline Delegacia de polícia & Delegacia, posto policial, batalhão de polícia \\
\hline Edificação comercial & Loja ou comércio \\
\hline Edificação de comunicação & $\begin{array}{l}\text { Edificação de transmissão de rádio/televisão, estação de } \\
\text { transmissão, emissora ou edificação de comunicação }\end{array}$ \\
\hline Edificação de ensino & Escola, universidade ou instituição de ensino \\
\hline Edificação de lazer & $\begin{array}{l}\text { Edificação de lazer, área de lazer, zona de lazer ou esporte, } \\
\text { espaço recreativo ou espaço para lazer }\end{array}$ \\
\hline Edificação de saúde & $\begin{array}{l}\text { Hospital, posto de saúde, edificação de saúde ou unidade de } \\
\text { saúde }\end{array}$ \\
\hline Edificação pública & $\begin{array}{l}\text { Prédio público, edificação pública, prefeitura ou prédio } \\
\text { administrativo }\end{array}$ \\
\hline Edificação religiosa & Igreja, templo religioso, prédio religioso ou edificação religiosa \\
\hline Farmácia & Farmácia \\
\hline Hotel & Hotel ou pousada \\
\hline Mercado & Mercado ou supermercado \\
\hline Ponto de ônibus & Ponto de ônibus ou parada de ônibus \\
\hline Posto de combustível & Posto de combustível, posto de gasolina ou auto posto \\
\hline Praça & Praça ou parque \\
\hline Restaurante & Lanchonete, padaria, restaurante ou local para refeição \\
\hline Semáforo & Semáforo, sinaleiro ou farol \\
\hline
\end{tabular}

Fonte: Os autores (2021). 
Baseado em Clarke (1989), utilizou-se o valor de 50\% para a validação do símbolo. Se 50\% ou mais dos participantes dos grupos 01 e 02 acertaram o significado do símbolo (resposta correta ou resposta correta associativa), o mesmo foi considerado eficaz, não havendo alterações em sua proposição. Caso contrário, a partir da experiência obtida nos testes, foi desenvolvido um novo símbolo pontual para representar a feição.

A Figura 3 apresenta a quantidade de acertos de cada grupo para os 19 símbolos desenvolvidos.

Figura 3 - Acertos no reconhecimento dos símbolos propostos

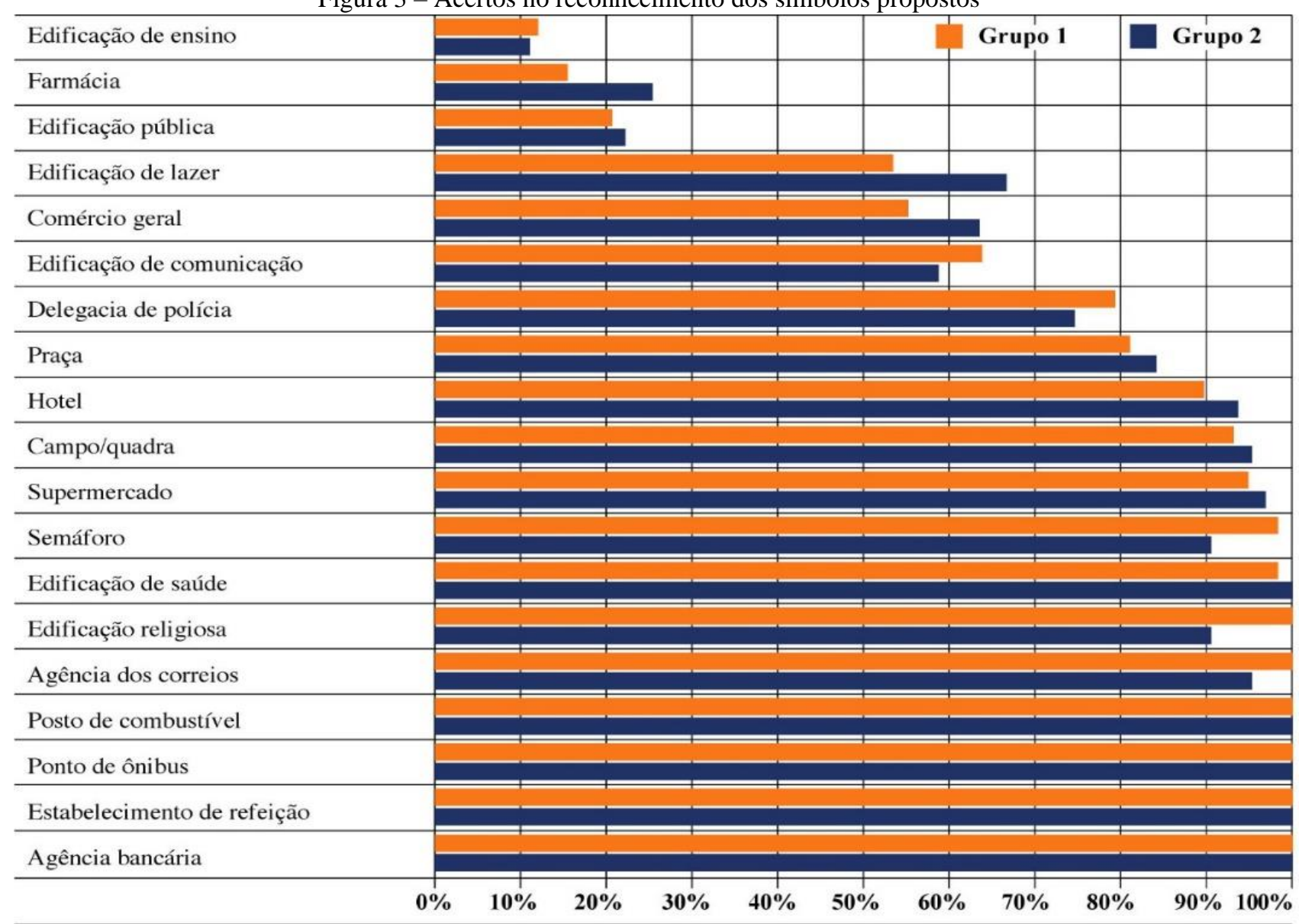

Fonte: Os autores (2021).

A assertividade no reconhecimento de muitos signos tem relação direta com a difusão de seu uso (CLARKE, 1989). Esta situação pode ser observada no caso dos símbolos de edificação de saúde, estabelecimento de refeição, ponto de ônibus, posto de combustível e semáforo, que tiveram alto índice de acertos no reconhecimento do seu significado. Os símbolos do estabelecimento de refeição, ponto de ônibus, posto de combustível e semáforo são amplamente utilizados em placas de trânsito. O símbolo da edificação de saúde é utilizado na representação de edificações de saúde em mapas topográficos e até mesmo em marcas de estabelecimentos médicos. Para Olson (1976) uma das maneiras de se melhorar o processo de geração dos mapas é através do treinamento do usuário. Se o usuário se habitua a associar um determinado símbolo ao seu referente, existe melhora gradativa na leitura dos mapas. Tal ideia converge para a afirmação de Sylvester (1952) de que a habilidade de ler e interpretar um mapa só pode ser adquirido gradualmente e com prática.

Os símbolos que representam a agência bancária, agência dos correios, campo/quadra, edificação religiosa, hotel, supermercado e praça tiveram assertividade no reconhecimento do símbolo maior que $80 \%$ para ambos os grupos. Conclui-se que isto se deve a boa associação semântica entre o símbolo e a feição que ele representa. $\mathrm{O}$ cifrão é imediatamente associado às instituições bancárias, o envelope (carta) à agência de correios, o carrinho de compras à supermercado e a cama ao hotel. No caso do campo/quadra o símbolo remete à atividade esportiva que é praticada no local (futebol), apesar do número maior de unidades compositivas, a simplicidade do símbolo foi suficiente para o reconhecimento do seu significado. Para o símbolo da edificação religiosa não foi necessário utilizar a cruz para associá-lo a feição de referência, as duas torres simétricas 
apresentadas no símbolo foram suficientes para compreensão do seu significado, e assim como ocorreu com o símbolo de campo/quadra, o maior número de unidades compositivas não interferiu no reconhecimento. No caso do símbolo da praça, os elementos banco e árvore foram associados pelos participantes à sua feição de referência. Estes resultados podem indicar que o número de unidades compositivas não influencia o processo de percepção da simbologia pictórica.

Os símbolos de comércio geral, delegacia de polícia, edificação de comunicação e de lazer tiveram assertividade menor que $80 \%$, ou seja, mais do que $20 \%$ dos participantes do teste não foram capazes de relacionar estes símbolos ao seu significado. Os símbolos de comércio geral, delegacia de polícia e edificação de comunicação foram desenvolvidos pelos autores, e por isto não estão na memória visual dos participantes. Arnheim (2011) afirma que o reconhecimento está relacionado com a experiência visual do indivíduo, uma das razões pelas quais estes símbolos tiveram menor assertividade no reconhecimento do seu significado.

Três símbolos não foram considerados eficazes, o de edificação de ensino, de edificação pública e de farmácia, os quais tiveram assertividade no reconhecimento do símbolo menor que 50\% em ambos os grupos. O símbolo que representa a edificação de ensino foi confundido com bibliotecas ou livrarias, acredita-se que isto ocorreu pelo fato de que o símbolo do livro é amplamente utilizado para a representação destes estabelecimentos. O símbolo da edificação pública foi confundido com indústrias e alguns participantes afirmaram que a bandeira representada no símbolo parecia com fumaça que saia de uma chaminé. O símbolo que representa a farmácia foi confundido com instituições de saúde (hospitais, clínicas médicas etc.) e muitos participantes afirmaram não saber qual o significado do símbolo.

Estes três símbolos exemplificam a situação na qual o significado semântico do símbolo proposto pelo desenvolvedor não foi reconhecido pelo usuário do mapa. De acordo com Joly (1990) é comum que signos percam seu valor simbólico quando retirados de seu contexto histórico ou sociocultural, situação que caracteriza falha na comunicação cartográfica. A partir dos resultados destes símbolos observa-se que a concepção de símbolos que têm uma relação semântica com o conceito a que se referem se torna desafiadora. A influência da cultura e da experiência visual se torna mais presente no processo de reconhecimento, muito mais do que os aspectos de simplicidade e simetria propostos pela teoria da Gestalt (ANDRADE. 2014).

Devido à baixa assertividade, optou-se por reformular os símbolos de edificação de ensino e edificação pública, o símbolo referente a farmácia não foi reformulado com o propósito de atender à recomendação do ano de 2018 do Conselho Federal de Farmácia (CFF) que sugere a utilização do símbolo já habitualmente relacionado a estabelecimentos de saúde utilizando o matiz verde, o qual já é amplamente empregado em países da América do Sul e Europa.

Somente cinco símbolos tiveram reconhecimento maior do seu significado pelos participantes do grupo 01: agência dos correios, delegacia de polícia, edificação de comunicação, edificação religiosa e semáforo. Os demais quatorze símbolos foram melhor reconhecidos pelo grupo 02, ou seja, aqueles apresentados com contorno e fundo branco.

Em uma avaliação global dos símbolos, a assertividade do grupo 01 foi de $76,58 \%$ enquanto que para o grupo 02 foi de $77,27 \%$. Os resultados demonstraram que a hipótese 04 , base para o desenvolvimento da tarefa 03 foi confirmada. Ou seja, o reconhecimento dos símbolos é favorecido quando existe maior contraste entre a figura e o fundo e quando o símbolo possui contorno. Os símbolos que continham estes elementos foram mais bem reconhecidos se comparados àqueles que não os continham. Entretanto, é possível verificar que mais importante que o contorno e o fundo branco é a composição visual do símbolo propriamente dito, visto que a taxa de assertividade no reconhecimento dos símbolos foi similar entre os dois grupos, variando em função do símbolo observado. Sendo assim, é possível afirmar que o contorno teve uma influência mais significativa na detecção e discriminação dos símbolos do que no seu reconhecimento.

Ao se observar a proporção da assertividade dos símbolos nota-se que a maior diferença entre os dois grupos foi para o símbolo que representa a edificação de lazer (13,22\%). Para os demais símbolos a diferença da assertividade não foi maior do que $10 \%$. Contudo, os símbolos que apresentaram baixa assertividade no reconhecimento do seu significado para o grupo 01, também o apresentaram para o grupo 02, caso dos símbolos de edificação pública e edificação de ensino. Esta análise também pode ser observada para símbolos com alta assertividade no reconhecimento do significado. 
Conclui-se em relação a esta tarefa que tão importante quanto a adição do contorno e do fundo branco em um símbolo é a coerência no desenvolvimento do símbolo com base no seu significado semântico para que o usuário do mapa seja capaz de rapidamente associar o símbolo a feição que ele representa. Além disso, os resultados indicaram que o número de unidades compositivas, assim como a simetria são fatores que sofrem menor influência no processo de reconhecimento.

\subsubsection{NOVOS SÍMBOLOS PROPOSTOS}

Os dois símbolos que tiveram baixa assertividade no seu reconhecimento, edificação de ensino e edificação pública, foram reformulados. Os dois novos símbolos foram desenvolvidos em preto (RGB - 0,0,0). O novo símbolo de edificação de ensino foi baseado no capelo, objeto comumente associado a formaturas escolares ou universitárias e que também é utilizado para representar edificações de ensino no Google Maps. Foram utilizadas poucas unidades compositivas e de forma simplificada, a fim de que quando o símbolo sofresse redução em função da escala de apresentação o seu reconhecimento não fosse prejudicado. O novo símbolo proposto para edificação pública representa duas bandeiras hasteadas, comumente utilizadas em frente às edificações públicas. As bandeiras são apresentadas tremulantes e com a haste maior a fim de evitar algum possível problema de identificação. Este símbolo também foi concebido de forma simples e com poucas unidades compositivas, apesar dos resultados obtidos na pesquisa não indicarem grande influência em relação a esta característica. A Figura 4 apresenta os novos símbolos concebidos.

Figura 4 -Novos símbolos desenvolvidos

\begin{tabular}{|c|c|c|c|c|c|}
\hline \multirow{2}{*}{ Feição } & Sem & Com & \multirow{2}{*}{ Feição } & Sem & Com \\
\hline & \multicolumn{2}{|c|}{ Contorno } & & \multicolumn{2}{|c|}{ Contorno } \\
\hline Edificação de ensino & & & Edificação pública & & \\
\hline
\end{tabular}

Fonte: Os autores (2021).

Os dois novos símbolos propostos não foram testados, sendo o teste sugerido para pesquisas futuras.

\section{CONCLUSÃO}

O objetivo deste trabalho foi propor, desenvolver e testar um conjunto de símbolos pontuais para o mapeamento topográfico em escala grande a partir de conceitos de percepção visual a fim de avaliar se os símbolos desenvolvidos são eficazes para as tarefas de detecção, discriminação e reconhecimento no contexto destes mapas. A partir dos resultados, concluiu-se que símbolos que possuem contorno quadrangular e se apresentam sobre fundo branco são mais bem detectados, discriminados e reconhecidos que símbolos apresentados sem tais elementos. As análises estatísticas comprovaram que os resultados encontrados são significantes e que, caso extrapolada a análise para uma população mais abrangente, os resultados encontrados tenderiam a se repetir.

Concluiu-se que o reconhecimento dos símbolos está diretamente ligado à sua utilização, ou seja, à experiência visual. Símbolos que são utilizados em diferentes contextos, sejam eles cartográficos ou não, são melhor reconhecidos se comparados àqueles que não são comumente utilizados. A partir desta análise, concluise que existe a necessidade do desenvolvimento de uma norma para padronizar os símbolos pontuais voltados para o mapeamento topográfico em escala grande no Brasil, a fim de que a simbologia seja efetivamente reconhecida pelos usuários do mapa e de que se minimize tanto o tempo do desenvolvimento dos produtos cartográficos quanto o tempo dispensado para realizar análises espaciais com estes produtos.

Os símbolos que possuem uma relação semântica com o conceito a que se referem têm um nível maior de dificuldade na sua concepção, já que a influência da experiência visual e da cultura se tornam mais presentes no processo de reconhecimento, muito mais do que os aspectos relacionados aos preceitos propostos pela teoria da Gestalt, tais como de simplicidade, simetria e número de unidades compositivas. Recomenda-se para trabalhos futuros que sejam realizadas análises que avaliem a aplicação destes símbolos no contexto do 
mapeamento interativo principalmente quanto aos aspectos de generalização cartográfica, a fim de analisar a percepção visual dos símbolos quando submetidos a mudança de escala. Outro aspecto relevante a ser discutido em trabalhos futuros é a influência dos símbolos pontuais na percepção das primitivas gráficas de linha e área, e como minimizar uma possível interferência.

Recomenda-se, ainda, que os símbolos propostos nesta pesquisa sejam testados com pessoas de diferentes faixas etárias, nível de escolaridade e até mesmo profissões, visto que o propósito do estudo é o mapeamento topográfico, com propósito de uso geral. Além disso, que sejam testados com pessoas de regiões distintas, a fim de verificar e validar a influência dos aspectos culturais na percepção e no reconhecimento dos símbolos testados.

Entre as contribuições, a metodologia aplicada para o presente estudo foi inteiramente desenvolvida utilizando softwares livres e gratuitos, os quais possibilitam que esta possa ser reproduzida para outras tarefas e conjuntos de símbolos por outros usuários ou pesquisadores. Os desafios apresentados estão sendo continuamente discutidos pelo Grupo de Pesquisas em Cartografia e Sistema de Informação Geográfica, com membros da Universidade Federal do Paraná (UFPR), Universidade Federal do Rio Grande do Sul (UFRGS) e outras instituições parceiras que, juntos, almejam o desenvolvimento da simbologia cartográfica.

\section{Agradecimentos}

Ao Programa de Pós-Graduação em Ciências Geodésicas da Universidade Federal do Paraná, aos voluntários que participaram do teste, os quais foram imprescindíveis para a realização deste trabalho e ao CNPq (Conselho Nacional de Desenvolvimento Científico e Tecnológico) - Processo 136090/2017-6 Categoria: Mestrado GM, pela bolsa de mestrado recebida pela autora principal.

\section{Contribuição dos Autores}

A autora Flávia Silveira participou na conceptualização, curadoria dos dados, análise formal, investigação, metodologia e na redação do artigo. A autora Adriana Alexandria Machado participou na visualização, redação, investigação, revisão e edição do artigo. As autoras Andrea Faria Andrade e Silvana Philippi Camboim participaram na conceptualização, investigação, metodologia, supervisão, revisão e edição do artigo.

\section{Compartilhamento dos símbolos no GitHub}

Os símbolos pontuais desenvolvidos foram compartilhados no Github do Laboratório Geoespacial Livre da Universidade Federal do Paraná (https://github.com/Labgeolivre-UFPR/Open Carto Symbols) nos formatos QML e SLD. A nomenclatura utilizada para os arquivos de estilo foi a mesma apresentada no artigo e referida a classe das feições da ET-EDGV Força Terrestre, $2^{a}$ edição que o símbolo representa. Este modo permite que o usuário relacione diretamente a feição com o seu respectivo símbolo.

\section{Conflitos de Interesse}

Os autores declaram que não há conflitos de interesse.

\section{Referências}

ANDRADE, A. F. A Gestalt na avaliação da simbologia pictórica com base em tarefas de leituras de mapas. Tese (Doutorado em Ciências Geodésicas) - Universidade Federal do Paraná, Curitiba, 2014.

ARAÚJO, V. S. de. NSDI-compliant reference map: experiences on implementing a user-centered cartographic symbology and standardized data modeling at large scale (1:2000). In SIMPÓSIO BRASILEIRO DE GEOINFORMÁRICA, 2016, Campos do Jordão. Anais do Simpósio Brasileiro de 
Geoinformática. Campos do Jordão, 2016. p. 117-127.

ARNHEIM, R. Arte e Percepção Visual: uma psicologia da visão criadora. Tradução de Ivonne Terezinha de Faria. São Paulo, 2011.

BLOK, C. A. Dynamic visualization variables in animation to support monitoring of spatial phenomena. Holanda, Netherlands Geographical Studies, 2005.

BOARD, C. Map reading tasks appropriate in experimental studies in cartographic communication. The Canadian Cartographer, Toronto, v. 15, p.1-12, Jan 1976. DOI. 10.3138/AG15-V252-3726-W346.

DENT, B. D. Cartography - Thematic Map Design. WCB/McGrawHill, 1999.

DEEB, R.; OOMS, K.; DE MAEYER, P. Typography in the Eyes of Bertin, Gender and Expertise Variation. The Cartographic Journal, v. 49, p.176-185, 2017. DOI. 10.1179/1743277412Y.0000000011.

DIRETORIA DE SERVIÇO GEOGRÁFICO (DSG). Manual Técnico de Convenções Cartográficas T34700 - $2^{\text {a }}$ Parte. Brasília, 2002.

DIRETORIA DE SERVIÇO GEOGRÁFICO (DSG). Especificações técnicas para representação de dados geoespaciais. Em X COLÓQUIO BRASILEIRO DE CIÊNCIAS GEODÉSICAS. Curitiba, 2018.

FEW, S. DataVisualization for Human Perception. The Encyclopedia of Human-Computer Interaction. Dinamarca, 2013. Disponível em: http://www.interactiondesign.org/encyclopedia/data_visualization_for_human_perception.html. Acesso em: 28 mai. 2019.

FORREST, D.; CASTNER, H. W. The design and perception of point symbols for tourism maps. The Cartographic Journal, v. 22, p.11-29, 1985. DOI. 10.1179/caj.1985.22.1.11.

GRANHA, G. S. P. Metodologia de criação de símbolos cartográficos: uma aplicação para estudos de impacto ambiental. Tese (Doutorado em Ciências Geodésicas) - Instituto Militar de Engenharia, Rio de Janeiro, 2001.

HEAD, C. G. The map as natural language: a paradigm for understanding. Cartographica, v. 21, n. 1, p. 132, 1984. DOI. 10.3138/E816-M074-8791-4506.

JOLY, F. A Cartografia. Campinas: Papirus, 1990.

KEATES, J. Cartographic design and production. Nova York, 1973.

MACEACHREN, A. Some truth with maps: a primer in symbolization \& design. Washington, Association of American Geographers, 1994.

OLIVEIRA, I. J. Cartografia dos impactos ambientais na Chapada dos Veadeiros. Mercator, v. 11, n. 4, p. 179-199, 2012.

OLSON, J. M. A. Coordinated Approach to Map Communication Improvement. The American Cartographer, v. 3, n. 2, p. 151-159, 1976. DOI. 10.1559/152304076784080177.

PETCHENIK, B. B. A map maker's perspective on map design research 1950-1980. Graphic Communication and Design Contemporary Cartography, 1983.

PISETTA, J. A. Base cartográfica do campus Centro Politécnico da Universidade Federal do Paraná. Projeto final (Graduação em Engenharia Cartográfica e de Agrimensura) - Universidade Federal do Paraná, Curitiba, 2018.

PREFEITURA MUNICIPAL DE CURITIBA. Consulta de bases. Disponível em: <https://www.curitiba.pr.gov.br/dadosabertos/busca/>. Acesso em: 18 ago. 2020.

ROBINSON, A. H. et al. Elements of Cartography. Nova York, 1995.

SANTIL, F. L. P.; SLUTER, C. R. Análise da percepção das variáveis visuais de acordo com as leis da Gestalt para representação cartográfica. Boletim de Ciências Geodésicas, v. 15, n. 4, p. 297-298, 2009.

SLUTER, C. R.; CAMBOIM, S. P.; IESCHECK, A. L.; PEREIRA, L. B.; CASTRO, N. C.; YAMADA, M. M.; ARAÚJO. V. S. de. Proposal of topographic map symbols for large-scale maps of urban areas in Brazil. The Cartographic Journal, v. 55, p. 362-377, 2018. DOI.10.1080/00087041.2018.1549307.

STIGMAR, H.; HARRIE, L. Evaluation of analytical measures of map legibility. The Cartographic Journal, 
v.48, n.1, p. 41-53, 2011. DOI. 10.1179/1743277410Y.0000000002.

SYLVESTER, D. Maps and Landscape. Londres, 1952.

TAURA, T.A.; SLUTER, C. R.; FIRKOWSKI, H. Generalização cartográfica das cartas do mapeamento urbano nas escalas 1:2.000, 1:5.000 e 1:10.000. Boletim de Ciências Geodésicas, v. 16, n. 3, 2010.

TRIOLA, M. F. Introdução à estatística. Rio de Janeiro, 1999.

\section{Biografia do autor principal}

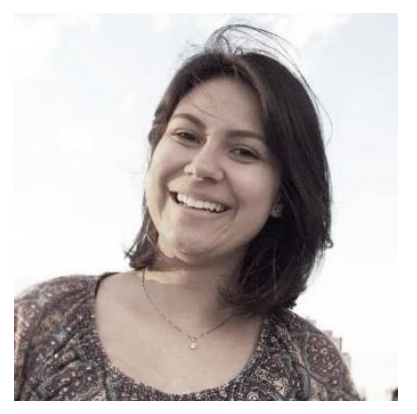

Flávia Silveira, nascida em Rio Negro - PR. Engenheira Cartógrafa e Agrimensora formada pela Universidade Federal do Paraná e mestre em Ciências Geodésicas pelo Programa Pós-Graduação em Ciências Geodésicas da UFPR. 